\title{
Mobilising Finance for WASH: Getting the Foundations Right
}

\author{
Lesley Pories ${ }^{1, *}$, Catarina Fonseca ${ }^{2}$ and Victoria Delmon ${ }^{3}$ \\ 1 Water.org, 117 West 20th Street, Kansas City, MO 64108, USA \\ 2 IRC WASH, Bezuidenhoutseweg 2, 2594 AV The Hague, The Netherlands; fonseca@ircwash.org \\ 3 The World Bank Group, 1818 H Street NW, Washington, DC 20433, USA; vdelmon@worldbank.org \\ * Correspondence: lpories@water.org
}

Received: 14 October 2019; Accepted: 9 November 2019; Published: 19 November 2019

\begin{abstract}
Responding to the substantial finance gap for achieving Sustainable Development Goals 6.1 and 6.2, the water and sanitation sector has mobilized to launch new blended finance vehicles with increasing frequency. The sustainability and scale-up of financial solutions is intended to support increased access to unserved, marginalized populations. However, without addressing foundational issues in the sector, any finance mechanism, whether public, private or blended, will be a short-term, band-aid solution and the sector will continue the cycle of dependency on external assistance. This paper presents the results of a collaborative effort of Water.org; the IRC water, sanitation and hygiene sector (WASH); and the World Bank Water Global Practice. Drawing from the latest research on effective public financial management and based on evidence from the countries where these organizations work, the paper demonstrates that sustainable success in mobilising finance on a large scale is dependent on a reasonable level of performance across 10 foundational areas. The paper presents evidence on the 10 foundational areas and discusses why other aspects of finance and governance, while necessary, are not sufficient. Better coordination amongst all development partners and governments, including a collective commitment to and prioritization of working on these foundational issues, is a necessary first step.
\end{abstract}

Keywords: finance; governance; water; sanitation; enabling environment; pro-poor; systems thinking

\section{Introduction}

There is an inherent challenge facing the water, sanitation and hygiene (WASH) sector-the sustainability of services for everyone. A substantial increase in sector financing is needed for governments to achieve Sustainable Development Goal 6 (SDG 6): "Ensure availability and sustainable management of water and sanitation for all."

WASH is an umbrella term used to broadly describe all of the infrastructure and the systems (institutions, people, finance and regulations) required to provide water, sanitation and hygiene services in the international development context. Estimates by The World Bank indicate that the present value of additional investment needed in WASH through 2030 will exceed USD 1.7 trillion [1]. Existing funding falls far short of this amount, with some countries needing to increase their investment in the WASH sector by up to six times.

The 2018/2019 UN-Water Global Analysis and Assessment of Sanitation and Drinking-Water reports that twenty countries and territories out of the 115 surveyed have a funding gap of $61 \%$ between identified needs and available funds. While there has been a modest increase in government water and sanitation budgets compared to the previous report (2016/2017), insufficient funding remains a serious issue for countries to achieve their national targets. Moreover, even though over two thirds of 
surveyed countries have policies and plans to reach poor populations, less than $40 \%$ of those have corresponding measures for financing these efforts that are consistently applied [2].

Faced with internal fiscal constraints and high debt levels, governments often have limited room to borrow to address that funding gap. Countries that do have access to Official Development Assistance (ODA) often also struggle to absorb it on account of structural deficiencies in public financial management and aid-delivery systems. Much of the available public and ODA financing will be needed for extending access to unserved and poorer populations in marginalised and remote areas. It will also be needed more generally for sanitation, as governments tend to prioritize water access when faced with an either/or decision [2].

There are only three sources of financing for water and sanitation services: taxes, tariffs and transfers. Currently, the combination of these funding sources is not enough to adequately address the need for water and sanitation services in developing countries. As governmental and donor funds cannot meet the funding needs on their own, involved stakeholders have concluded that more commercial finance needs to be attracted into the sector, alongside a similar increase in public finance [3].

Commercial finance generally seeks a low-risk, dependable return on investments (ROI). Commercial lenders want to see that a borrower is financially healthy and well-managed (i.e. "credit worthy") and that the basics are covered, including [4-6]:

- A clear legal mandate and scope for service provision;

- Financial capacity—a solid financial track record with a positive net cash flow over several years;

- Strong management-including business-minded leadership, operational efficiency and strong performance; financial capacity (i.e., strong revenues to cover costs of operations and debt services); and good asset management and business planning;

- Track record of borrowing and repaying debts;

- An asset base against which collateral can be taken.

WASH sector service providers in most developing countries meet few, if any, of these requirements. Shortcomings that undermine the sector's ability to attract finance include underdeveloped national financial sectors; a lack of vision by governments to seek alternative sources of finance; ineffective regulation; low cost recovery; weak governance; a mismatch between supply and demand of finance; low service provisions and the operational efficiency of urban and rural WASH service providers; and a lack of anti-corruption measures $[7,8]$.

Furthermore, the bulk of investments needed to fulfil the SDG 6 mandate to leave no one behind and reach the poorest first require the supply of water and sanitation to more remote, less urbanised or poor neighbourhoods, which are likely to be less commercially viable. Thus the expectation is not only that commercial finance should enter into a sector which it already views as more risky, but also that it should focus on the least commercially viable segments of that sector. However, from 2012 to 2017, private finance targeted for the sector amounted to USD 2.1 billion, representing paltry $1.4 \%$ of the total private finance mobilized, mostly through guarantees [9]. Blended finance mechanisms have not reached scale to date: success is largely dependent on the ability to mobilise local commercial investment, which is not feasible in poorer and remote areas.

Attracting commercial finance into the WASH sector of developing countries has proven to be a hard sell that has been largely unsuccessful to date. Paul Horrocks, Manager for the Private Finance for Sustainable Development initiative at the Organization for Economic Cooperation and Development (OECD), observed [10] that "over the past 4 years [2014-2017], \$81 billion of development funding was mobilized from the private sector. Only 1.9 percent of this amount was mobilized for water. The WASH sector is, despite the demands and needs, not doing well."

The WASH sector in most emerging markets is perceived as a high-risk sector, despite the reality that the provisions of water supply, sanitation and hygiene, often in markets with little competition, actually have the components of lower-risk investments if the correct foundations are in place. This is 
the case in most OECD countries where commercial investments in water service providers are seen as low-risk.

Domestic lenders in developing countries, however, have limited experience lending to WASH service providers. Lenders typically deny credit to local WASH initiatives because the projects and/or service providers are unable to generate sufficient revenues to cover the costs of borrowing. When they do offer finance, it is often on terms that meet their risk-averse nature but which are incompatible with service provider realities: short term loans at high interest rates, requiring extensive collateral. Moreover, transaction costs are prohibitively high to the majority of borrowers, due to complex transactions associated with lenders' risk mitigation measures.

To manage some of these challenges and encourage commercial lending, the development community has started promoting financing mechanisms that blend commercial finance with grants or guarantee debt service payments, allowing for lower interest rates and longer tenors. The rationale behind blended finance is to make water and sanitation investments more commercially viable for investors and catalyse private investment in developing countries by de-risking individual projects and schemes. However, the few isolated experiences with blended finance in the water sector to date, supported by international donors, have predominantly been in middle-income countries and failed so far to be replicated at scale [11]. The reason is clear: moving to scale requires a concerted focus not on the blended mechanisms developed to incentivise commercial lending, but on the broader foundational issues facing the sector that feed the commercial sector's reluctance to invest.

Until these foundational issues are substantially addressed, any finance mechanism - public, private or blended - will be a short-term, band-aid solution that inadvertently perpetuates the existing cycle of dependency on external assistance rather than resolving the root causes and building self-sufficiency.

\section{Materials and Methods}

This research is a collaborative effort of Water.org, IRC WASH and the World Bank Water Global Practice. Drawing from an extensive (grey) literature review (mainly all the financial assessments and country-scoping studies to which the authors had access), the latest research on effective public financial management and evidence from the countries where these organizations work, the authors compiled a short list of about 30 foundational issues. These 30 issues were reduced to 10 through a process of elimination that ensured no remaining issue has examples in existing literature where its absence was not an insurmountable impediment to success. For instance, the authors identified that the presence of an independent regulator, although widely considered important, is not always necessary for attracting additional finance if the remaining foundations are otherwise resolved (e.g. Uganda).

The World Bank has considerable access to data regarding governance and finance on urban water supply and sanitation; IRC has the same for rural water supply and sanitation. Water.org catalyses large scale financial mechanisms targeted at the bottom of the lowest wealth quintile in 13 countries, wielding considerable data about low-income household investments as well as repayment rates.

Countries and cases revised include: Benin, Burkina Faso, Burundi, Ethiopia, Ghana, Ivory Coast, Kenya, Lesotho, Liberia, Madagascar, Mali, Morocco, Mozambique, Nigeria, Rwanda, Senegal, South Africa, Tanzania, Uganda, Zambia and Zimbabwe (in Africa); Afghanistan, Bangladesh, Bhutan, Cambodia, India, Indonesia, Maldives, Lao, Pakistan, Philippines and Vietnam (in Asia); and Brazil, Chile, Colombia, Costa Rica, El Salvador, Haiti, Mexico, Paraguay and Peru (in Latin America). By a method of successive exclusion, and based on concrete country examples, the authors grouped and selected 10 foundational issues that they concluded were crucial to attracting more finance into the sector.

The latest data sources include JMP (UNICEF), GLAAS (WHO), OECD data sets and global reports. The co-authors additionally draw upon the breadth of expertise resident in their organizations to write and highlight case studies that offer examples of pitfalls to avoid, as well as how to overcome the challenges. More than twenty interviews were conducted during 2018 to complete examples and 
develop the cases mentioned in this paper. The paper was additionally reviewed by approximtely 15 sector experts.

\section{Results}

The evidence shows that, while each country and service provider will have different strengths and weaknesses, sustainable success in mobilising finance on a large scale is dependent on a reasonable level of performance across 10 foundational areas. This section exclusively focuses on the evidence for those 10 foundational areas.

\subsection{Governance at the Sectoral Level}

Providing access to water and sanitation services for the entire population of developed countries has required a combination of private and public finance. However, the WASH sector in developing countries has historically been unattractive to commercial lenders. While governments and donors may support poor-performing, weak service providers - and the provision of water and sanitation is uncontroversial and therefore politically salient, regardless of performance - commercial lenders cannot afford that luxury-their business model is predicated on loans being serviced and repaid. They are appropriately cautious about lending to borrowers that are not credit worthy, which is the status of many WASH service providers in developing countries, regardless of whether they are large or small, and whether they serve urban or rural populations.

Reluctance to lend is compounded if at the sector level, there is limited planning and regulation, transparency and accountability, and few perceived avenues for recourse, should an investment default. Strengthening these sectoral foundations would help build the confidence of commercial investors. Governments and donors should explore what can be done or with whom they can partner to mitigate these foundational issues to appeal more strongly to commercial lenders (domestic as well as international) as well as enhance the long-term sustainability of investments.

3.1.1. Planning and Financing Strategies for Maximising Public and Commercial Funds to Achieve Social Objectives

Data about national WASH sector budgets are notoriously hard to extract, as illustrated by Figure 1, which draws on an assessment of 37 countries conducted by the Sanitation and Water for All Partnership (SWA) in 2017. In many cases, this is because WASH expenditures are spread between various government ministries (such as health, agriculture, rural development, urban planning, etc.) to the point that governments themselves are hard-pressed to extract all the composite information.

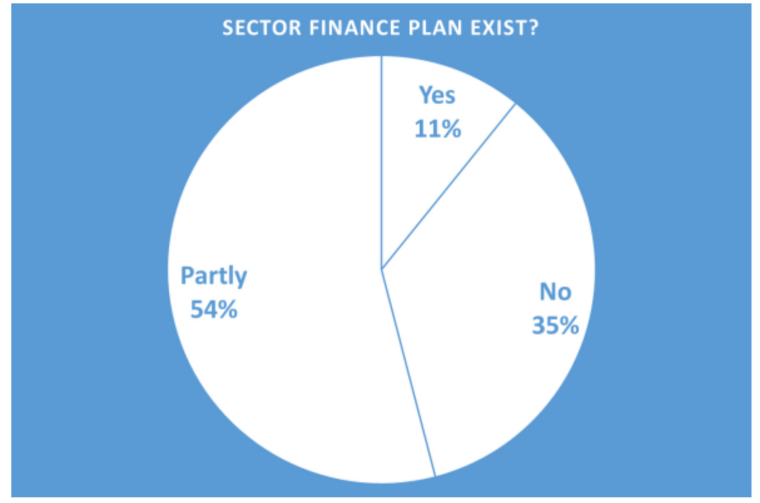

(a)

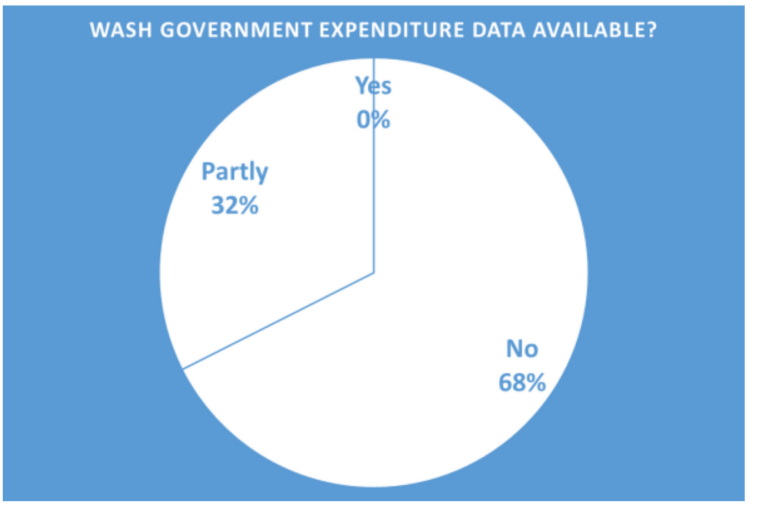

(b)

Figure 1. (a) Water, sanitation and hygiene (WASH) sector finance plans; (b) WASH expenditure data availability. 
The lack of a unified plan indicates the lack of a strategy, which not only prevents progress from being monitored and managed, but also prevents parties from being held accountable for underachievement. At present, very few countries have WASH sector finance plans, government expenditure reports or other accountability instruments that provide accurate assessments on how finance is being used in the sector [12]. Sector finance plans are critical for a) establishing comprehensive strategies for governments; b) setting priorities, goals and targets at the national level; c) prioritising investments and funding sources (whether through tariffs, taxes or transfers); and d) determining how public and commercial funds can be maximised to meet all (or most) national objectives. While every government has made national commitments for SDG 6, they have not necessarily developed plans for achieving and financing these commitments [2], leaving considerable doubt that they will be realized.

A comprehensive financing strategy that utilizes public finance (national and sub-national), private finance (debt, management contracts and public-private partnerships) and tariffs is essential for a healthy, sustainable foundation. Where public policies require that tariffs be low, these strategies need to build in public finance to compensate for the lost revenue. Current practices often deploy scarce public funds for WASH for urban projects or to de-risk private finance as part of large projects that are of little benefit to the poor, such as water supply or sewerage networks in the wealthier areas of cities. One WASH finance expert recalls [13], "When subsidies from the European Commission started flowing to Southern Europe, the regions that benefitted the most from grant money were the urban areas and the larger utilities because they had projects prepared. Fully subsidized capex went to Lisbon and Madrid. That was very unfair for the unserved in the rural areas."

While political realities will probably never eliminate the practice of subsidizing the projects that need it the least, financing plans give governments the tools to identify investments and how to finance them, ideally prioritising public fund allocations for schemes that are less attractive for private investment and/or which serve marginalised populations.

Governments can also look to incentivise performance through performance-based grants. An example of this is the newly-developed National Urban Water Program (NUWAS) in Indonesia, where the government, with World Bank Group (WBG) assistance, has developed an incentive-based framework for urban water supply. The NUWAS framework requires local governments and their water utilities (PDAMs) to agree on a performance target in order to receive funding from the central government. The framework is also designed to create incentives for local governments and PDAMs to continuously improve their performance by accessing further funding or technical assistance (TA) from the program [14].

Sector level planning is also crucial to ensure that public funds are effectively directed to the more difficult sub-sectors. A coordinated sector strategy would help governments focus on how to finance their goals with a tariff policy focused on cost recovery, allowing public funds and subsidies to be reserved for the less attractive investments-typically sanitation, rural water supply and water supply to more marginalised or remote urban areas - while gradually decreasing subsidies for mainstream urban water supply which is more appealing for commercial investors.

A powerful example of what can be achieved when political will is fully activated was demonstrated by India, where the national sanitation campaign, Swachh Bharat Abhiyan, included a specific timeline (October 2015 through October 2019) for achieving total eradication of open defecation and a dedicated budget that was carefully administered via two different ministries with dedicated staff at all levels of implementation: the Ministry of Drinking Water and Sanitation for the rural workstream and the Ministry of Urban Development for the urban. State-level targets were closely monitored and widely reported via a vibrant, multifaceted social media campaign that also featured popular movie stars, athletes and the Prime Minister, Narendra Modi. These efforts had an impact: in 2014, Indians formed 60 percent of the global population who defecated in the open; the country's share in 2018 was estimated at 20 percent, according to Indian government officials [15]. The country was declared open defecation free (ODF) at the conclusion of the campaign, and while some experts are sceptical of this achievement, the advancement made was monumental and arguably unprecedented in a 
democratic country. A notable contrast that also speaks to the power of political will can be observed in South Korea's path to near-universal water and sanitation coverage starting in the late 1960s; those similarly impressive achievements, however, were achieved via an authoritarian government [16] that was able to institute all required changes from the top down rather than developing detailed programmes for incentivizing and encouraging its citizens to change their ways.

\subsubsection{Effective Tariff-Setting Practices and Economic Regulation}

Revenues from tariffs are the most predictable source of financing for WASH providers. In both emerging and developed markets, tariffs are often set well below what is needed to recover basic operational and maintenance costs of service providers [11]. This is generally seen as politically expedient, given widespread public perception that water is a basic necessity that should be provided by their government at the absolute minimum cost (if not free). However, limiting the most direct source of revenue for water and sanitation providers perpetuates a cycle of sector inefficiency that leads to the neglection of assets; lack of assets and business planning; and a subsequent dependency on aid: When tariff revenues are insufficient for covering operational costs, commercial lenders will be reluctant to disburse loans to a water or sanitation services provider, as they need to ensure that there is a sufficient and constant operating surplus to service the debt over the maturity period.

In the absence of tariff revenue and commercial finance, infrastructure erodes and levels of service decline, leading customers to be even less willing to pay for services. With no alternatives, WASH providers turn to government funds and/or aid to meet their minimum requirements, and meeting only the minimum means that the existing status quo (i.e. low service levels) is maintained. Thus the cycle repeats itself, and public and/or donor funds are consistently used to maintain low levels of service with no viable way forward.

In addition to adequate tariff structures being in place, an effective regulatory environment for the WASH sector is essential to ensure the delivery of affordable, high-quality and sustainable services to citizens. WASH services (particularly piped water and large sewage networks) constitute a natural monopoly - only one provider can utilize a piped network at a time, and the average homeowner in a developed country does not have the option of selecting a different provider from their neighbour. If unchecked, service providers may overcharge or provide poor quality services. Economic regulation of WASH services was initially introduced in developed countries to oversee private service providers, whether under license (England and Wales) or through contract (France) and is intended to limit service providers from potentially abusing that monopolistic power.

Publicly-owned service providers have traditionally not been regulated to the same extent as private ones on the assumption that government control could strike the right balance between cost recovery, affordable tariffs and acceptable levels of service. In the last two decades, however, regulation of public utilities has been growing in response to the deteriorating quality of WASH service delivery. This approach has led to several benefits, notably de-politicising tariff-setting and providing independent oversight. Countries as different as Portugal, Australia, Peru and Colombia are using regulation as part of the mix of policy instruments that ensure that public utilities offer improved value and quality services to the public [14].

Attention should be given to which entity is responsible for recommending and setting tariffs. Where rates are set by parliament or a local political entity, decisions are more likely to be politicised. This vulnerability to political mismanagement contributes to commercial lenders' perception of the sector as high-risk. Some objectivity and consistency can be introduced by shifting the responsibility for tariff-setting or approval to a provincial or central regulatory body that is more removed from the people directly affected. An independent local or national-level regulator can help to manage this risk, too, but it has proven challenging to give regulators in developing countries both requisite autonomy to be truly independent and sufficient resources to operate effectively. Thus, the optimal solution will depend on local circumstances. 
An example of the autonomy challenge is Kenya, where tariffs are reviewed by WASREB - the national regulator-and there is a clear tariff-setting process and methodology set out in guidelines that follow the enabling legislation (WASREB Tariff Guidelines). Despite this strong structure, however, the Constitution of Kenya requires final decisions on tariffs to be at the county (a political territory roughly the equivalent to a U.S. state.) level. This means that while the regulator recommends tariff rates, the relevant local authority determines the tariff. A Deutsche Gesellschaft für Internationale Zusammenarbeit (GIZ) study (2018) observed that several Kenyan utilities have struggled to maintain their tariff levels in the face of political pressures. Even though the regulator supported tariff increases, political considerations often trumped technical financial considerations. In many cases, utilities in Kenya did not apply for a tariff increase, even though the regulator encouraged and requested them to do so, suggesting that political considerations were at play [7]. There are also cases in Kenya where tariffs were approved in line with the regulator's recommendations, and they supported improvements which led to commercial finance being raised, with the support of donor collaboration.

Many reports draw a strong connection between high technical performance and the absence of negative political interference and corruption [7,14,17-19]. Burkina Faso is one example where the political will of the government and the autonomy granted to ONEA, the national urban water utility, in carrying out its mandate, has been a determining factor of the utility's success [7]. Three-year performance contracts were established between the government and ONEA in 1993, with oversight of those contracts strengthened in 2008 through a multi-stakeholder committee.

Governments are advised to establish a clear framework and methodology for tariff-setting and review, with an emphasis on cost recovery. While it may not be realistic to depoliticize the process of pricing a public good, as this is typically seen as the domain of government, the process for tariff-setting should be as objective as possible, and clearly outlined to provide transparency and consistency and ensure that tariffs have some correlations with costs and their increase over time. The methodology can also be used to support policy objectives by incorporating incentives for the efficiency and high performance of service providers and cross-subsidising lower-income areas with revenues from higher-income users [20]. The regulator can then monitor performance of the service provider and implement the efficiency incentives.

One way to ensure that revenues of a service provider do not fall behind inflation is to index-link the tariff. National Water and Sewerage Corporation (NWSC), the utility responsible for urban water delivery in Uganda, was able to negotiate an indexation of the tariff with its parent ministry. This meant that the tariff would increase automatically in line with inflation and other agreed core cost drivers. The result of this indexation was that NWSC did not have to apply for a tariff increase or adjustment for many years and it was still able to sustain positive operating cash flows over a long period of time [7].

When setting tariff policy, the affordability of the tariffs and willingness to pay should be considered. In some cases, higher tariffs may be justified for different customer groupings, such as industry or commercial premises. Popular tariff structures, such as increasing block tariffs (ICTs), in which higher tariff rates are charged once consumption increases above a threshold (i.e., block) level, allow for cross-subsidisation. However, these structures usually do not include mechanisms for restricting access to the lowest tariff block to qualifying low-income users, meaning that wealthier customers receive water at the same subsidized rate if their consumption falls within the lowest block. Allowing such subsidies to be exploited by all instead of only those who need them is an inefficient use of scarce financial resources [21]. Moreover, ICTs only serve people who are currently connected to piped water networks, meaning they completely bypass those most desperately in need.

Clustered or merged service providers covering areas that are larger areas wider than their administrative boundaries, e.g., municipalities and rural villages, could create conditions to channel support to their least viable areas by providing conditions for cross-subsidisation of the overall population served by the same utility. 


\subsubsection{Adequate Performance Regulation and Transparent Accountability Mechanisms}

For banks and investors, the performance and accountability levels of water service providers in developing countries are too often still an unknown. The foundation of a healthy investment climate includes stronger sector regulation, with well-documented standards and targets for performance; clear lines of accountability; and incentives and penalties for performance. Credit ratings or an acceptable substitute are another critical component of an investment-ready landscape.

At face value, the water sector should have built-in advantages in terms of performance indicators, global standards and monitoring. The International Benchmarking Network for Water and Sanitation Utilities (IBNET) is the world's largest database for water and sanitation utility performance data. IBNET supports and promotes good benchmarking practices among water and sanitation services by providing guidance on indicators and definitions; facilitating the establishment of national or regional benchmarking schemes; and undertaking peer group performance comparisons. It includes performance data and benchmarks from more than 200 countries. These performance standards can immediately help service providers compare themselves across a global spectrum of peers [22,23].

Financial and budgetary monitoring mechanisms at central and service provider levels are less uniform, however, and these systems are critical for governments to understand achievements and hold relevant authorities accountable-especially those outputs that are more social in nature and are not built into standard benchmarking indicators. Accountability mechanisms in the sector include joint sector reviews and parliamentary reviews at the central level. Ministries and regulatory agencies also carry out monitoring and benchmarking, but in many countries, limited resources are made available to ensure effective monitoring, leaving the performance of service providers to be largely self-reported. Oversight of rural WASH providers is even less common. This is partly because of the practical challenges - including the cost - of overseeing remote service providers, although such challenges can increasingly be addressed with mobile technology [12].

Few developing countries have yet developed credit rating systems that could provide potential investors with a base for determining if a WASH investment is credit-worthy. The establishment of shadow credit ratings in lieu of official ones can be an interim measure that addresses this foundational shortcoming and provide a mechanism to assess utility credit-worthiness. In Latin America, the Inter-American Development Bank (IDB) and the International Water Association (IWA) co-developed AquaRating, a system based on an international standard for the evaluation and improvement of water and sanitation utilities [24]. While not explicitly designed to be a shadow credit ratings system, it measures technical performance; financial, environmental and operational performance; and corporate governance, and is being used by some actors to measure the performance of water utilities before extending a loan. These actors include the Millennium Challenge Corporation (via IWA) in Africa and Asia, as well as the Asian Development Bank in several countries, including the primary water utility in Fiji [25]. Today, more than 60 water and sanitation companies across the world use AquaRating to improve their performance and efficiency in water resource management [26].

The level of integrity in a government and a sector is also important for investors to give them comfort that their investments will be used for the designated purposes. Accountability benchmarking and credit ratings can provide such assurances.

Kenyan regulator WASREB collaborated with The World Bank to develop a mechanism to assess utility creditworthiness. In 2011, shadow credit ratings for 43 Kenyan utilities were published, which gave borrowers and lenders an objective overview of creditworthiness and risk. Thirteen utilities were given investment-grade ratings and another 16 utilities were rated "near-investment." Together with WASREB's IMPACT report, which documents the performance of Kenya's water services sector, the ratings provided utilities with a diagnostic tool with which to identify areas for improvement. Recent technical assistance supports capacity building at sector institutions to increase the commercial viability of the sectors. This has included creditworthiness training for service providers, preparing shadow credit-ratings and results-based lending with support from the regulator and an analysis of existing debt from Water Service Boards that is now being transferred to the Water Service Providers. 
It helps service providers interested in commercial borrowing by providing a toolkit to strengthen financial management, project modelling and business plan writing [27].

\subsubsection{Clarity of Mandate and Performance Obligations of Service Providers}

Service providers, public or private, will naturally focus on the most accessible and well-off parts of the service area, where operational costs are low and revenue recovery is perceived to be high; therefore, making profitability appear more likely.

An example of the natural tendency of service providers to serve wealthy areas can be seen in Vietnam, where the provincial water service companies (PWSCs) have historically been owned by the Provincial People's Committees (PPCs), which also set tariffs and oversee service delivery. There are no performance agreements between the PPCs and the PWSCs setting out performance indicators or access targets, so there are limited incentives for the PWSCs to expand access within their official service areas, particularly to poorer areas. Not surprisingly, PWSCs typically focus on the more densely populated and accessible parts of their service area. These issues may be exacerbated as the PWSCs undergo the process of being equitized under government policy (i.e., divesting part of the shares to private ownership); the connection with the PPC diminishes, meaning that the focus on densely populated and accessible areas is likely to increase unless performance agreements are put in place that mandate serving harder to reach areas. Monitoring of the PWSCs is also limited. The government is currently reviewing how to strengthen the service delivery and financial sustainability of service providers to improve the outcomes of the equitization process [28].

To ensure that rural and urban WASH service providers serve all their communities and not just the most convenient and/or wealthy parts of their service areas, there needs to be a clear long-term mandate (included in concession contracts where applicable). Performance indicators need to be clearly specified and monitored, with incentives and penalties that encourage delivering services and expanding access to those who are harder to reach.

In Cambodia, private service providers have operated under three-year licenses with limited performance indicators. They were unable to raise commercial finance on suitable terms due to the short duration of their mandates and were not incentivised to expand their systems to increase access. In 2014, the Government of Cambodia introduced longer-term licenses that were coupled with specific targets for performance and access [29]. It is expected that this reform will unlock opportunities for service providers to access commercial finance on better terms so that they can fulfil their commitments to increased access and better service provision while ensuring better accountability and service performance.

\subsection{Service Provider Level}

Because WASH provision is considered a public good, governments (developed and developing alike) often feel pressure to keep tariffs low. Leigland et al. [11] observe, "Based on data from 605 developing country utilities in the IBNET database, just 17 percent of these utilities cover their Operation and Maintenance costs and create a surplus that could potentially be used to mobilize commercial borrowing." If revenues from tariffs do not cover the costs of operation, much less costs of capital investment (capex) and financing, then service providers cannot carry out long-term asset management, fund capex out of revenues or raise finance. As a result, WASH service providers have grown dependent on grant funding from budget allocations and ODA to finance investments. WASH comprised 57 percent of total ODA flows to the water sector from 1995 to 2014 [30].

This dependency on grant funding has effectively reduced the need for WASH providers to "act like a business," focus on service delivery and customers or have the organisational capacity to repay loans. It has also reduced the incentive to set water user tariffs at a rate that covers operational costs or build up financial reserves. Finally, it has also led to limited attention on building organisations that have the organisational and financial management underpinnings to be considered credit-worthy. 
To improve or extend service coverage, WASH service providers increasingly need to secure finance beyond government or donor grants. This is new territory for the majority of providers who are used to relying heavily on government funds, often in the form of non-repayable grants, and focusing on building and maintaining assets rather than building their businesses and customer bases to generate revenues and repay loans. This puts them at a disadvantage when applying for other sources of finance. Commercial lenders will lend money only to credit-worthy borrowers that are able to service their debts and have a good performance track record [31].

\subsubsection{Improved Financial and Operational Management and Efficiency}

Service providers can only attract commercial finance if they can demonstrate that their finances and operational performance are in good shape. Part of this proof is that they can show that their revenues and tariffs are sufficient to cover the costs of operations. It is important to show a track record of financing management and transparency. This can be achieved through requiring audited and published financial accounts and feeding them into available credit rating systems [32] as discussed above.

They will also need to demonstrate operational efficiency and good performance, which will mainly be demonstrated through mechanisms for tracking and monitoring operational performance; benchmarking performance against that of other service providers, such as IBNET [22]; improving operating efficiency and instituting incentives; and instituting penalties for performance. These are initiatives that a regulator can support, especially where operations are decentralised to the regional or local level.

For service providers that have low levels of efficiency, there is extensive guidance and examples of how to improve. The need for patience in order to turn utilities around and attract commercial finance can be demonstrated by the experience of NWSC, the Ugandan utility discussed in Section 3.1.2. The utility was losing money and performing poorly, even after years of intensive investment. A new manager was appointed in 1999 who introduced accountability and performance metrics for company officers and set an operation plan for a 100-day turnaround programme, with performance targets and a monitoring mechanism. Performance improved dramatically, and further reforms were implemented after the programme. While some improvements were achieved in a very short space of time, it took far longer for the utility to achieve a satisfactory credit rating and be comfortable about seeking commercial finance. As of January 2019, 20 years after the initial 100-day turnaround plan, NWSC had just sought domestic currency loans from the national banks (approximately $\$ 15$ million) and was awaiting the Ministry of Finance's approval. Proceeds of the loan will be used to expand water service coverage nationally, scale up sewerage works and support household connections [33]. This example illustrates the dual importance of utility governance and leadership in the short-term as well as long-term, coupled with political and government support [34].

\subsubsection{Capacity Strengthening for Business Planning}

A business plan helps a business identify short and medium-term objectives and an action plan for achieving those objectives. For WASH service providers, a business plan typically-specifies the baseline for performance using key performance indicators as well as an end-line (e.g., where the service provider wants to be in five years); describes the activities that will move it from the baseline to the end-line over that given period of time (either structural or non-structural); and provides corresponding costs and financing mechanisms. To ensure they prepare to meet the SDGs, the business plans should also set out how they will serve the underserved parts of their service areas, what the projected costs will be, and how this will be financed. The plan then needs to articulate a strategy for connecting those new households.

Building the capacity of WASH service providers to operate like a business is also a challenge. In the offices of public WASH service providers, staff consist primarily of engineers and other technical workers who focus on keeping the systems functioning. Financial planning and business skillsets are 
often less emphasised, as those functions have traditionally been managed more centrally or simply were not needed. To connect new customers and service areas to piped systems, service providers need to demonstrate that the service they offer is superior to their current source in terms of quality as well as reliability, and is worth the extra cost. This requires strategic planning and behaving like a salesperson-a skillset that public service providers have not traditionally honed.

IBNET itself acknowledges that, "The amount people who are prepared to pay for water is the biggest obstacle to achieving the Sustainable Development Goals for water and sanitation" (IBNET Tariffs Dashboard, 2019 [23]). Strong financial management and client connection plans are critical foundations for a WASH service provider to operate with self-sufficiency. Business planning, asset management planning and determining optimal cashflows all feed into these plans and serve as the components for a strong project preparation plan that is provided to a commercial investor.

In 2015, Narra Water Supply System, a municipal water utility in the Philippines, took a 20-year loan from the Municipal Development Fund Office (MDFO) of the Philippines Department of Finance to extend services to cover all 23 villages within the municipality, a significant expansion beyond the three villages that were being served at the time. Construction of new facilities began immediately, but active recruitment of new paying customers for the services was not prioritised. Narra Water management realised that rapid client acquisition was needed to generate the revenues required for meeting the instalment payments on the loan and received technical assistance (TA) from Water.org in September 2017. The first focus was improving customer acquisition: mapping the community to understand where new potential clients were located and developing outreach strategies for these prospective customers. TA was also provided on financial management. They calculated that a monthly revenue of one million Philippine Pesos (approximately USD 18,460) per month was required while they were still in the grace period of the loan, and that this revenue could be achieved only when 4300 households were connected and paying water tariffs to the Narra Water Supply System. After one year of collaboration with Water.org, 1500 new households were connected to the system, bringing the utility much closer to the 4300 households needed to cover operating expenses and make interest payments against its loan. This also positions Narra Water to reach the 6000 client households that will ensure timely payment of principal and interest due by 2020.

Strong project preparation is particularly critical for successful WASH applications for commercial finance, since water infrastructure assets are difficult to use as collateral for loans because assets used by water utilities are often owned by the government (and therefore not legally available as collateral) [6]. Experts express this sentiment by noting the scarcity of bankable projects. Leigland et al. observe [11], "At present, there is more money available than there are viable projects attractive for commercial finance." This is the main reason why so many donors and governments are supporting project preparation to build a pipeline of viable commercial investments.

Efforts to build the internal capacity of WASH service providers should be strengthened and scaled. Capacity strengthening and specific TA can be tailor-made for different contexts (from less formal district providers to more urban and formalised utilities). Examples where this support is being implemented with success are highlighted below.

Batang District Water Supply Company, located in Central Java, Indonesia, is an Indonesian regional water supply company (PDAM). The company partnered with Water.org in September 2016 to grow the number of low-income clients it served. One component of achieving that goal was client-facing: not only offering a wider range of financing options that catered to the needs of this market segment, but advertising these financing options to potential clients. The PDAM was already offering some financial services to its clients, but sought Water.org's TA to increase its efficiency and advertise the services it had on offer. Additional TA on market analysis and demand generation was also provided. The second component of serving more low-income clients required expanding pipelines and services to more areas where this population lived. That expansion required additional funds. Water.org provided TA to develop standard operating procedures (SOPs) for financial service offerings, financial recordkeeping and reporting and human resources recruitment. Having these 
SOPs in place positioned the PDAM as more attractive to investors when applying for the credit they needed to expand, and in 2018 the PDAM secured approximately USD 51,552 in grant funding from the Indonesian government to extend their pipeline, enabling them to serve an additional 5000 households. In this context, successful application for public funds represents a step forward in the process to receiving commercial investment. As of August 2018, 4968 new households were connected to the Batang District water supply system, and the PDAM increased the number of clients using internal financing from 70 per month to 248.

Waternet, the public water company of Amsterdam, is currently supporting SOMAGEP-SA, one of Mali's public water supply companies, to attract larger investments. SOMAGEP-SA is responsible for the drinking water supply in 17 major urban areas throughout the country and faces significant challenges in delivering high-quality water to its customers. Waternet provides capacity-building assistance (funded via grant money from the Netherlands government) to improve utility performance enhancement. That was followed by small loans from the Dutch Development Bank (FMO), which are aimed at improving energy efficiency and reducing non-revenue water. The aim is for the utilities to have the required performance and track record to attract larger concessional and commercial finance [35].

In 2007, The World Bank launched a pilot programme with Kenyan microfinance institution K-Rep Bank to help rural and peri-urban communities access loan financing for improving and expanding small piped-water systems. TA was provided to develop bankable loan applications and supervise project implementation. This pilot was scaled up, and \$21 million of results-based grants have been provided to help water service providers obtain commercial funds for delivering water services to low-income areas. These projects have provided water access to over 300,000 people, with another 200,000 expected to benefit by the time the last project closes in December 2019. As of 2018, approximately 50 transactions were completed, raising more than $\$ 25$ million in private capital. The experience demonstrates an emerging project pipeline and growing appetite among utilities for blended financing to bridge the investment gap. Utilities are gaining experience at executing commercially bankable projects, and there is growing interest among local banks to lend to the water sector, with four banks now actively participating, and others looking to enter the market. The U.S. Agency for International Development's (USAID's) Development Credit Authority supported many of these loans through credit guarantees that provided partial risk cover to domestic lenders. These efforts directly complement the Netherlands-funded Kenya Pooled Water Fund, which is planning to pool together assets to issue larger, risk-diversified private bonds [36].

These case studies highlight the essential nature of operations and marketing-improved customer targeting; better financial and administrative management; and capital finance plan creation-to enable a WASH service provider to secure finance, be it public or commercial. Any investment requires confidence in the receiving entity's ability to manage its funds and transform them into positive outputs, whether it is the extension of services to low-income groups (a more social or government priority) or efficient cost recovery to ensure financial sustainability (a more commercial or private investor priority).

The examples also help set expectations about the speed of institutional change: helping WASH service providers access commercial finance may often require a phased approach to ensure that the target institution is ready to manage commercial or blended solutions and their associated levels of complexity.

\subsubsection{Enhanced Autonomy and Legal Framework}

Many urban WASH service providers are departments of municipalities, with no financial autonomy. Often, these departments do not have clarity on their cost base, revenues, nor how much funding they will be allocated. They typically do not have their own business functions but rely on those of the municipality for services such as accounting, human resources, vehicles, etc. Electricity costs, which typically make up a large component of costs for the WASH service provision, are often not 
passed onto the department, rendering efficiency audits and incentives difficult. The mandate of such a department is often vague, and performance indicators are often absent.

Commercial lenders will generally find it difficult to lend to the WASH provider rather than the municipality as it is not a separate legal entity, even if they may in some circumstances be able to support specific ring-fenced projects. In such circumstances, governments looking to secure commercial finance for their WASH providers should consider ring-fencing the activities of the WASH provider by corporatising the department into a separate legal entity or outsourcing a set of activities through a contract to a third party.

Service providers might also consider adopting an autonomous structure that allows for greater flexibility in rewarding staff for good performance, such as limited company or corporation structures, rather than public entities, which are typically constrained by civil service pay scales and may not allow for performance-based incentives to staff. This can have a significant impact on the ability of the service provider to reward and retain good staff.

Rural WASH providers are often small and informal. Their mandate is unclear, as they may have been given a basic license to run a business which is not tailored for water supply, as was the initial licensing regime in Cambodia discussed in Section 3.1.4. Similarly, in rural Vietnam, WASH providers are developed and operated as privately financed schemes that were initially conceived as business development proposals by private sector actors and then approved by the provincial authorities as "investment decisions," often with no clear specifications on service areas, performance requirements or access targets. In other countries, the service provisions of rural schemes is carried out by loosely-formed local communities which may not have a separate legal identity, nor be able to enter into contracts or raise finance. In most instances, such WASH providers have limited capacity and there is little monitoring of performance.

Governments should consider how to formalise these arrangements and create clearer mandates and performance requirements, as was done in Cambodia [29]. They could also consider achieving economies of scale that might increase the professional capacity and bankability of the service providers through clustering schemes, as in the case of Benin below.

In 2010, The World Bank initiated a project to help improve water supply and distribution services in rural and small towns of Benin. Ten pilot schemes covering a total of 41,000 people were grouped into four clusters, each of which was tendered as a separate PPP transaction. Private operators bid for the eight-year concession agreements for the design, partial financing, rehabilitation, extension and operation of the schemes. The bidding process led to the selection of three winning local bidders for the four clusters. The four concession agreements were signed in August and September 2014. Following the successful pilot, rural clustered concessions are now being scaled up with a follow-on World Bank project, which is helping to design and prioritise the projects and providing support to blended finance instruments to help the bidders get commercial domestic finance on affordable terms [37].

\subsection{Supply of Finance}

Traditional suppliers of finance to the WASH sector in developing countries, mainly for capital expenditure, include development banks, bilateral and multilateral agencies, NGOs and governments through budget allocations. The goal is to maximize the impact of those traditional sources and to crowd in new potential sources, such as commercial banks, pension funds and impact investors.

Integrating two disparate types of investor, broadly categorized in this paper as public and private, has so far proven challenging in many developing countries. Available data from The World Bank Private Participation in Infrastructure (PPI) database suggests that private WASH investments in the least developed countries (LDCs) are limited to a handful of large-scale infrastructure investments. Domestic private finance is not always available in many emerging markets, and where it is available, it is usually limited to microfinance. 
As discussed in previous sections, the WASH sector in many developing countries is not yet attractive to private sector investment, and this paper has highlighted areas where the sector can be strengthened at government/sector and service provider levels to make it more attractive. Traditional suppliers of finance to the WASH sector, therefore, need to coordinate to support these initiatives and innovate to help attract new sources of finance into the sector.

USAID's Water, Sanitation and Hygiene Finance (WASH-FIN) programme has sought to do this through a collaboration with national governments, development partners, service providers, local financial institutions and other stakeholders to close financing gaps and improve governance structures that enable target-countries to access reliable sources of capital for sustainable, climate resilient water and sanitation infrastructure. Two years of operating this programme across seven countries to date has led the team to conclude [38]:

- Market finance is abundant and available - provided its risk-versus-reward terms are met—and is needed to close the infrastructure financing gap for services.

- There is no shortage of finance globally; there are excess funds available for investment through both simple and sophisticated private financial systems and instruments.

\subsubsection{Rectifying the Mismatch between Commercial Bank Risk Profiles and WASH Sector Realities}

Commercial lenders, as a rule, seek to minimise risk while maximising returns. As noted above, the WASH sector in developing countries is often less attractive because of foundational issues.

The reluctance of a commercial bank to invest in the WASH sector may go beyond a specific bank's perception of sector risk. In some countries, commercial banks are not allowed (e.g., Ethiopia) or are limited in how much they can provide loans at the sub-national level. This section discusses: acceptable collateral, loan tenor, size and complexity.

As identified in Section 3.2, domestic commercial banks in developing countries are less familiar with lending to water utilities. It may also be difficult for lenders to take collateral over WASH assets-in some countries this is illegal. Even if they can do this legally, they would be constrained from enforcing the collateral and selling those assets, as many are underground and would be hard to unearth and resell. Moreover, while water's designation as a "human right" is widely acknowledged, appropriate and critical, it can undermine water as an investment opportunity in the eyes of some lenders, as they subsequently perceive water and sanitation as a "public good."

It is difficult for private lenders to exercise step-in rights (rights that give lenders, on the occurrence of certain events, the right to take over the borrower's shares or assets) over assets deemed to be public, and water assets are often categorised in this way. Frequently, the only collateral service providers have is the regular cash-flow coming from consumers paying their tariffs. As discussed elsewhere, if the revenues from tariffs do not provide a surplus, then securing tariffs as collateral will be difficult. For smaller private service providers, this can lead to lenders requiring collateral from the service provider owners' other assets, such as vehicles, real estate and other fixed transfers from the national government. Finally, in some markets, the lack of clarity between the role of sub-government authorities and service providers also undermines investment opportunities.

WASH sector assets are expected to last a long time, so projects are amortized over a long period (ranging from 10 years up to 40 years). However, most capital markets in emerging markets cannot lend beyond seven to 15 years, meaning that there is a mismatch between the financing and the asset life. In addition to this, most providers, even small ones, need more money than they can realistically borrow. They are building "backbone" infrastructure and strictly financing this through commercial debt is costly, meaning there is an additional mismatch between the demand for money and the supply that can be provided.

At the same time, financing requests from service providers are often either not large enough or too complex to be attractive for development banks who need economies of scale to make the cost of doing business worthwhile. "There are very high transaction costs of pushing forward projects that are interesting but complicated in set-up," observes Nick Marchese of the European Investment 
Bank [39]. "The investment banks face limits in developing blended options for anything smaller than several million Euros." The issue of how to deal with foreign currencies so that neither investor nor borrower loses too much from exchange rate fluctuations adds additional costs, complexity and time to any transaction.

Complexity is likely to be a reality for the foreseeable future. Fixing the foundational issues is also a process that requires time and patience, and the actors involved would benefit from adapting their expectations to meet contexts that differ from those in the developed commercial markets. Development stakeholders can assist private investors to manage their expectations for these vehicles, build their comfort levels with this complexity and see the long-term payoffs. They may also be able to do more of the facility design work in the front-end to reduce the need for private investors to develop a complex system that works (e.g., make it easier to 'plug and play').

Belief in the big idea that the combination of technical services and access to financial capital that enables water service providers (WSP) to improve and expand services led Catholic Relief Services (CRS) and local partners to design a strategy to unlock private sector finance to improve and expand water and sanitation services in El Salvador. The Azure model mobilizes technical support and investment capital tailored to water and sanitation service providers in rural communities and small towns. In El Salvador, WASH services outside the large cities are often provided by independent community associations or municipal operators, which face challenges in accessing commercial finance because they are seen to be high risk borrowers: interest rates are typically very high and loan amounts are relatively small.

To provide WSPs access to loans that are affordable and large enough to meet their needs, CRS and local partners under the Azure model are providing engineering and business development services to WSPs, at affordable rates, brokering loan negotiations between local financial institutions and WSPs and providing capacity building, support and monitoring to help them repay their loans. Since piloting in 2015/2016, local finance institutions (including banks and credit cooperatives) have accrued loans totalling $\$ 521,000$ to WSPs, and there have been no defaults on these loans to date. More than 70 additional WSPs are currently seeking TA and access to finance to improve and expand water and sanitation services. After the success of these first loans, local financial institutions expressed interest in expanding loans to additional WSPs but needed additional capital to do so. In response, CRS collaborated with the Inter-American Development Bank (BID-Lab) to set up an investment vehicle called Azure Source Capital (ASC) to provide capital to local financial institutions to on-lend to WSPs.

ASC raises capital through impact investors, then disburses these funds through a trust (FideAgua) established in El Salvador. FideAgua is administrated by the Development Bank of El Salvador (BANDESAL), which uses FideAgua to loan capital to local finance institutions at market rates, who then on-lend to WSPs. Azure technical services are funded by grants from CRS, BID-Lab, fees charged to WSPs and by the revenues earned by ASC, as per their regulations, to ensure that WSPs are functioning and capable of operating their services, generating revenue for operations and maintenance and repaying loans. By the time the Azure concept took shape in El Salvador, CRS had already spent a decade building relationships and ensuring a sound enabling environment. These conditions included an open, non-risk averse financial sector, empowerment of decentralised water utilities, people who were willing and able to pay for piped water services and an environment where grant funding did not crowd out commercial financing. TA included developing modalities for impact investment in water and sanitation, and educating various partners at regional, international and local levels. The team observes that replicating the Azure model in places where these environmental context features are not as favourable will inevitably encounter different conditions and require a different set-up [40].

There may also be opportunities to standardize approaches in respect to public-private partnership transactions, as demonstrated by the case from India. The Ganga basin supports over 500 million people, more than 200 million of whom are below the poverty line. Pollution from domestic wastewater accounts for 80 percent of the pollution load and only half of the wastewater generated on the Ganga is treated. Thirty percent of the wastewater treatment plants monitored in the basin are non-functional 
and only 5 percent meet relevant discharge standards. Due to low cost recovery (less than 30 percent) for sewerage services in the basin states, operations and maintenances (O\&M) expenses are paid out of budget funds and are typically under-funded.

To address these concerns and to make contractors more accountable, the Government of India (GoI) turned to the hybrid annuity model (HAM) contracting approach, under which the private sector designs, builds and operates the facility. It also finances up to 60 percent of the capex investment. This is repaid, along with financing charges and O\&M fees, through periodic annuity payments during the O\&M period of the concession, typically 15 years. The GoI, with IFC transaction advisory support, developed standard bidding documents to streamline and standardize private contractor solicitations for concessions. So far, three projects have reached financial close and eight more are in different stages of preparation and bidding. The government portion of the capex for three projects is being funded from a World Bank loan.

The market is becoming comfortable with the risk allocation and it has created a new market for primarily domestic developers. Using this model, projects are now being prepared and bid out relatively quickly. Significant handholding was required to support the GoI in developing this approach, including analytical studies; consultative workshops with private sector and banks; and transaction advisory support.

When considering capacity building in the WASH sector, the focus tends to be on the demand side of finance: on assisting service providers to build their operations and business cases to be more attractive to commercial lenders. Helping the domestic finance suppliers-the investors-see the opportunities for financing WASH and how small adjustments to making transactions can improve the risk profile for these loans is an equally critical aspect of the enabling environment.

Grants can be used to build the skills of commercial banks, and pension regulators and securities commissions, so that they better understand how investments in the water sector can match their long-term liabilities. In Kenya, a set of tools has been developed to help banks evaluate investments in the WASH sector, and that has been rolled out successfully, to the extent that banks are now extending finance to service providers [41].

\subsubsection{Avoiding Mechanisms That Can Result in Market Distortions}

Some governments and development actors have explored incentives to "open" up local financial markets to the WASH sector. However, some of these initiatives can give rise to market distortions and impede progress towards sustainability.

One approach to opening WASH markets has been to allow or encourage actors to target new WASH loan products to low-income clients. While permitting this new market to flourish, governments and other stakeholders sometimes strive to protect low-income borrowers from being exploited by predatory lenders. One protection mechanism has been to set limits upon the interest rate margin charged on microlending. (The interest rate margin is the spread between the interest rate an on-lender obtains their bulk loan and the interest rate they charge a borrower; fundamentally serving as a transactions fee.) While this margin cap may be well-intentioned, there is still not enough evidence for the long-term impact of this action on the larger objectives of making local finance more readily available or opening WASH markets.

A 2016 regulatory change in Kenya capped the maximum lending rate at no more than four percent above the Central Bank base rate. The current base rate is nine percent, meaning that the maximum lending rate is 13 percent, a rate which does not allow the lender to recover their costs on higher-risk loans. This has led to a steep decline in issue of microloans in Kenya, so that poorer borrowers are denied formal banking opportunities and may have to seek (or return to) informal solutions, like loan sharks or mafia-like water distribution systems that can dictate the price. Reuters reported [42] in August 2018 that, "As a result [of the interest rate margin cap], lending to the private sector fell from 9.3 percent in 2016 to 2.4 percent last year," and that, "Many thousands of Kenyans, now unable to access bank lending, have turned to more expensive borrowing." 
In 2015, the Government of the Netherlands funded a five-year project in Ghana aiming to boost WASH services for households and small/medium enterprise (SME) WASH institutions in-country. The project budget was six million Euros, of which four million were allocated to a revolving fund for lending and two million for TA to financial institutions, SMEs and households to accelerate private sector involvement in WASH [43]. The main financial instrument used was the revolving fund, which lent funds to micro-finance institutions (MFIs) willing to on-lend for WASH at an interest rate of 10 percent, as opposed to the 30 percent that was locally available. (MFIs specialise in microlending to low-income borrowers.)

The maximum on-lending rate that a borrowing institution can charge to a client is limited to 17 percent for a 12-month loan. However, the seven percent difference is too low for the MFIs in Ghana to recuperate their costs. In a World Bank assessment of WASH financing options in Ghana, Steel and Darteh [44] observed that on-lending institutions in Ghana need to charge at least 24 percent over a 12-month period to cover basic operating costs, and above that amount to be sustainable and competitive against other uses of capital (Steel, W.F. and Darteh, B. 2018). This inability to recover costs makes the revolving fund unattractive to larger lending institutions. Steel and Darteh confirm: “As of March 2018, about $€ 2$ million has been lent to 24 MFIs for on-lending-mostly small NGOs in the northern part of the country. Larger MFIs [ ... ] generally have not taken up these funds because of the limited spread between the wholesale rate of 10 percent and the 17 percent ceiling placed on the retail rate that they can charge."

There are many opportunities for providing TA and capacity-building to the supply side of finance, but a more comprehensive understanding of the long-term implications of policies is required. As long as market distortions exist, regardless of how well-intentioned, private finance will not be able to compete.

\subsubsection{Targeting Development Finance for Maximum Impact}

This section is primarily concerned with multilateral and bilateral development agencies, as they continue to make the lion's share of investments in the sector: Bilateral funders contributed 66 percent of all ODA financing to the water sector over a 20-year period, from 1995 to 2014. Multilateral funders have been growing their share over the same 20-year period; while collectively contributing 32 percent of total ODA commitments to the water and sanitation sector over the 20-year period, their share grew to become consistently over 60 percent since 2010 and peaked at 71 percent in both 2011 and 2013 [30].

The longstanding presence and activity of development actors in WASH may be one of the most complicated, foundational bottlenecks to overcome in order to attract commercial investment into the sector at a scale that can realise the achievement of SDG 6. While many stakeholders understand the internal adjustments that need to be made, the WASH teams in development banks, multi and bilateral agencies and many NGOS that work on these issues operate within their own institutional constraints and mandates. Communicating the need for procedural change, gaining institutional buy-in and then overseeing the requisite change management that would subsequently follow will be a serious undertaking.

While many development finance actors are structured with knowledge, expertise and institutional mandates to deliver the majority of their impact through loans and repayable finance (usually to governments), other development actors, including philanthropic organisations and large NGOs, have traditionally provided grant funds at country or local level directly to targeted beneficiaries. With the SDG 6 finance gap in mind, some of this latter category are now re-orientating their activities towards lending and supporting blended finance mechanisms.

To ensure the maximum impact of available grant and concessional finance to the WASH sector, and that it is targeted towards increased access and improved service delivery, strong coordination will be needed between all of the traditional suppliers of finance. 


\section{Discussion}

Governments have committed to SDG 6.1 and 6.2, and finance is essential to achieving those goals. The supply of finance into the WASH sector is insufficient to achieve the SDGs, but it is also heavily focused on infrastructure investment or discrete projects, with limited focus on sector reforms, strengthening of the enabling environment and removal of bottlenecks in the flow of financial resources. Governments, who are responsible for repaying concessional debt, typically chose to borrow from multilaterals for project focused interventions or infrastructure rather than for financing major sector reforms. Using public finance, concessional finance and private finance to construct "backbone" infrastructure (i.e., production and transmission infrastructure such as treatment plants and major underground piped networks) is the way that most newer OECD countries have funded bulk water infrastructure. Israel, Australia, Korea and Singapore have all used a version of this approach.

Governments and development donors have typically rewarded and ensured the sustainability of impressive country-level reforms by providing further support to the high performers. However, after implementing successful reforms, those sectors or utilities may qualify for commercial finance at market rates. For countries to be able to extend concessional or grant finance to service providers in the next tier down, such as sanitation providers or the smaller water utilities who serve marginalised or more rural markets, they may need to consider encouraging the stronger utilities to turn to the commercial markets while reserving the concessional and grant finance for smaller, less successful service providers.

Countries like Senegal, Kenya and Uganda have driven impressive service provider reforms and improved performance, with several WASH providers now on the verge of being credit-worthy. However, until recently, concessional and/or grant finance has continued to be made available to them, making it unlikely for the WASH providers to turn to commercial finance. This approach has been slowly changing in Kenya, and now is in Uganda, with the stronger utilities now seeking commercial finance. Suppliers of finance can encourage wider uptake of this practice in order to help direct concessional and grant finance to the WASH providers who serve rural and harder-to-reach populations in alignment with the SDG commitment to leave no one behind.

The development finance community is already helping governments to move towards this more targeted approach. For example, The World Bank's Maximizing Finance for Development (MFD) approach, is encouraging increased targeting in how its loans are deployed. It is also looking to make more of its lending in the WASH sector output-based or linked to development policy reforms through development policy operations (DPO).

To ensure that development finance does not crowd out commercial finance, development actors need to adopt their own ways of assessing whether an investment is capable of attracting private finance before making concessional finance available. Focus could be on making less commercially appealing projects and service providers credit-worthy and funding the least commercially-viable projects. Consideration also needs to be given to finding less costly WASH solutions for poorer and more remote communities.

All of the recommendations in this paper require coordination and cooperation between different levels of government and with and between development partners. Some duplication could be avoided, and impact enhanced, with greater coordination between these actors to focus on achieving SDG 6 . Coordination could include geographic presence to ensure all parts of a country are receiving attention and that no one is being left behind, for example, or the types of activities could be strategically coordinated to align with the strengths of each development actor involved.

Guidelines and frameworks for increased coordination exist: The Busan Partnership, developed at the Fourth High-Level Forum on Aid Effectiveness in 2011, offers a framework for continued dialogue and efforts to enhance the effectiveness of development cooperation. The Addis Ababa Action Agenda (2015) provides a new global framework for financing sustainable development, particularly the Sustainable Development Goals, by aligning all financing flows and policies with economic, social and environmental priorities. Development stakeholders should unite around activating these frameworks 
and ensuring general buy-in. Getting all actors to use the same standards for promoting the same goals could build confidence between development partners and reduce confusion for governments.

Attracting the necessary finance to the sector will depend increasingly on the strength of the enabling environment. This research identified 10 key foundational issues, which can be further grouped under three stakeholder categories (Figure 2):

- The governance, institutional, policy, tariff and regulatory arrangements to ensure transparency, consistency and sustainability (grey box with foundational issues 1 to 4 );

- The technical and financial efficiency of service providers to sustain creditworthiness (light blue box with issues 5 to 7 );

- $\quad$ Issues related to the supply and suppliers of finance (dark blue box with issues 8 to 10).

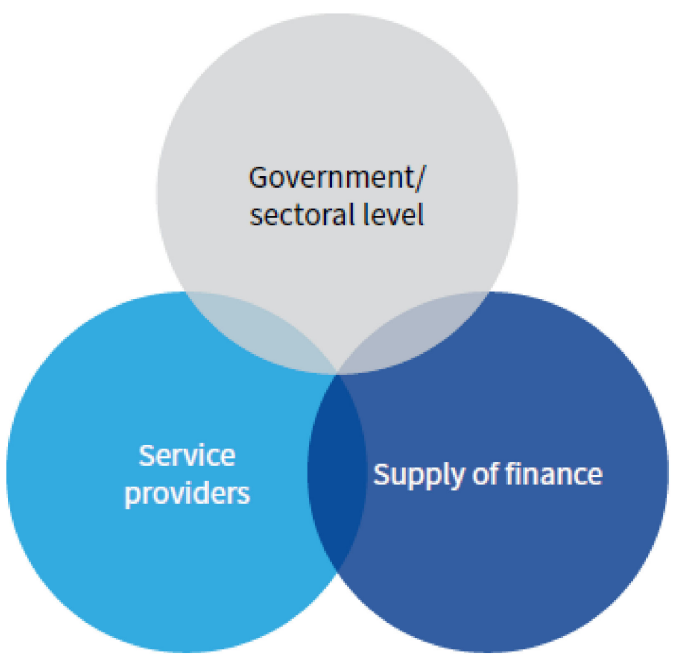

5. Solid financial and operational management

6. Capacity strengthening for business planning

7. Enhanced autonomy and legal framework
1. Planning and financing strategies for maximizing public and commercial funds to achieve social objectives

2. Effective tariff-setting practices and economic regulation

3. Adequate performance regulation and transparent accountability mechanisms

4. Clarity of mandate and performance obligations of service providers

8. Rectifying the mismatch between commercial bank risk profile and WASH sector realities

9. Avoiding mechanisms that create market distortions

10. Targeting development finance for maximum impact

Figure 2. Ten foundational issues to mobilise finance for WASH grouped by stakeholder categories.

Investing time, energy and funding into getting the 10 foundations right will establish a healthy enabling environment that can support the long-term investments in the sector to ensure that all people have access to clean water and sanitation, as evident from several countries.

Better coordination amongst all development partners and governments, including a collective commitment to and prioritization of working on these foundational issues, is a necessary first step. Financial accountability incentives, such as key performance indicators and payment-by-results types of instruments should be adopted by development finance actors and key sector ministries, and efforts should be made to enhance WASH stakeholder understanding of finance ecosystems.

Each country and service provider will have different strengths and weaknesses across all three categories, requiring varied needs and assorted levels of urgency. This nuance understood, sustainable success in mobilising finance at large scales is dependent on a reasonable level of performance across all 10 foundational areas.

While new finance vehicles should help draw in more commercial finance by hedging some risks and inherent constraints associated with lending to WASH providers, the sustainability and potential for scaling these financial solutions will require complementary investment in addressing basic foundational issues in the enabling environment, as characterised above. Moving forward, 
this categorization can provide guidance to governments and development agencies on where to focus their efforts, working towards a common vision.

Author Contributions: Conceptualization, L.P., C.F. and V.D.; data curation, L.P. and C.F.; formal analysis, L.P., C.F. and V.D.; investigation, L.P. and V.D.; methodology, L.P., C.F. and V.D.; validation, L.P. and C.F.; visualization, C.F.; writing—original draft, L.P., C.F. and V.D.; writing—review and editing, L.P., C.F. and V.D.

Funding: This research received no external funding.

Acknowledgments: The authors would like to thank the reviewers and contributors to the research. Namely: Rajesh Advani, Alexander Bakalian, Maren Barbee, Louis Boorstin, Sergio Campos, Corinne Cathala, Richard Damania, José Tomás Frade, Hein Gietema, Jeff Goldberg, Paul Hicks, Ella Lazerte, Patricia Lopez, Claire Lyons, William Kingdom, Joel Kolker, Hannah Kovich, Ian Moise, Patrick Moriarty, Matt Morrison, John Moyer, Mary Ngunjiri, Laura Ralston, Regina Rossman, Gustavo Saltiel, Stef Smits, William Steel and Rich Thorsten. Additional acknowledgements are extended to representatives from bilateral agencies who have met with Water.org and IRC periodically over 2018.

Conflicts of Interest: The authors declare no conflict of interest.

\section{References}

1. Hutton, G.; Varughese, M. The Costs of Meeting the 2030 Sustainable Development Goal Targets on Drinking Water Sanitation and Hygiene; Water and Sanitation Program Technical Paper; WSP/The World Bank: Washington, DC, USA, 2016; Available online: https://openknowledge.worldbank.org/bitstream/handle/10986/23681/ K8632.pdf?sequence $=4$ (accessed on 16 February 2019).

2. World Health Organisation. National Systems to Support Drinking-Water, Sanitation and Hygiene: Global Status Report 2019; UN-Water Global Analysis and Assessment of Sanitation and Drinking-Water (GLAAS) 2019 Report; World Health Organisation: Geneva, Switzerland, 2019.

3. Fonseca, C.; Pories, L. Financing WASH: How to Increase Funds for the Sector While Reducing Inequities: Position Paper for the Sanitation and Water for All Finance Ministers Meeting; IRC Briefing Paper; IRC: The Hague, The Netherlands, 2017; Available online: https://www.ircwash.org/resources/financing-wash-how-increasefunds-sector-while-reducing-inequalities-position-paper (accessed on 11 February 2019).

4. Amanda, G.; Alex, B.; Bill, K.; Gustavo, S.; Yogita, M.; Gerard, S.; Joel, K.; Vicky, K. Reform and Finance for the Urban Water Supply and Sanitation Sector; World Bank: Washington, DC, USA, 2019.

5. Alvarez, V. Back to Basics: Sound Utility Business Plans as a First Step in the Sustainability Ladder. 2019. Available online: http://blogs.worldbank.org/water/back-basics-sound-utility-business-plans-first-stepsustainability-ladder (accessed on 26 February 2019).

6. Bender, K. Introducing Commercial Finance into the Water Sector in Developing Countries; The World Bank: Washington, DC, USA, 2017; Available online: http://documents.worldbank.org/curated/en/ 423121488451451957/Introducing-commercial-finance-into-the-water-sector-in-developing-countries (accessed on 11 February 2019).

7. Eberhard, R. Improving Access to Urban Water Sustainably in Sub-Saharan Africa and Beyond: A Way Forward for German Development Cooperation and its Partners Based on a Review of Two Decades of Involvement in Urban Water Sector Reforms in Africa. 2018. Available online: http://www.oecd.org/water/GIZ-Access-Study-Part-II\%E2\%80\%93Narrative-Report-Away-forward-for-German-Development-Cooperation-and-its-Partners.pdf (accessed on 20 January 2019).

8. Goksu, A.; Trémolet, S.; Kolker, J.; Kingdom, B. Easing the Transition to Commercial Finance for Sustainable Water and Sanitation; The World Bank: Washington, DC, USA, 2017; Available online: http://www.oecd.org/environment/resources/Session\%204\%20Easing\%20the\% 20transition\%20to\%20commercial\%20finance\%20for\%20WSS.pdf (accessed on 26 February 2019).

9. OECD. Making Blended Finance Work for Water and Sanitation: Unlocking Commercial Finance for SDG 6, OECD Studies on Water; OECD Publishing: Paris, France, 2019.

10. Horrocks, P. Blended Finance for Water Investments; presentation at 2018 Stockholm World Water Week; OECD: Paris, France, 27 August 2018.

11. Leigland, J.; Trémolet, S.; Ikeda, J. Achieving Universal Access to Water and Sanitation by 2030: The Role of Blended Finance; WB Working Paper; The World Bank: Washington, DC, USA, 2016; 
Available online: http://documents.worldbank.org/curated/en/978521472029369304/Achieving-universalaccess-to-water-and-sanitation-by-2030-the-role-of-blended-finance (accessed on 14 January 2019).

12. Van de Lande, L.; Fonseca, C. Global Review of National Accountability Mechanisms for SDG6; End Water Poverty: London, UK, 2018.

13. Frade, J.; Stockholm, Sweden. private conversation, 28 August 2018.

14. Mumssen, Y.; Saltiel, G.; Kingdom, B. Aligning Institutions and Incentives for Sustainable Water Supply and Sanitation Services; The World Bank: Washington, DC, USA, 2018; Available online: https://openknowledge.worldbank.org/bitstream/handle/10986/29795/126016-WP-P159124PUBLIC-7-5-2018-12-14-46-W.pdf?sequence=1\&isAllowed=y (accessed on 11 February 2019).

15. Swachh Bharat Progress Key to UN Sustainable Development Goal on Open Defecation. The Hindu, New Delhi. 27 September 2018. Available online: https:/www.thehindu.com/news/national/swachh-bharatprogress-key-to-un-sdg-on-open-defecation/article24886738.ece (accessed on 31 January 2019).

16. Cummings, C.; Langdown, I.; Hart, T. What Drives Reform? Making Sanitation a Political Priority in Secondary Cities; Overseas Development Institute: London, UK, December 2016; Available online: https://www.odi.org/ sites/odi.org.uk/files/resource-documents/11262.pdf (accessed on 11 Novemeber 2019).

17. United Nations (UN). Financing for Development: Progress and Prospects. 2018. Available online: https://www.un.org/development/desa/publications/financing-for-development-progress-and-prospects2018.html (accessed on 29 January 2019).

18. Winpenny, J.; Camdessus, M. Financing Water for All: Report of the World Panel on Financing Water Infrastructure; aka Camdessus Report; World Water Council: Marseille, France, 2003; Available online: http://www.worldwatercouncil.org/fileadmin/world_water_council/documents_old/ Library/Publications_and_reports/CamdessusReport.pdf (accessed on 26 February 2019).

19. World Water Council (WWC). Increasing Financial Flows for Urban Sanitation; World Water Council: Marseilles, France, 2018; Available online: http://www.worldwatercouncil.org/en/publications/increasingfinancial-flows-urban-sanitation (accessed on 21 January 2019).

20. Mumssen, Y.; Saltiel, G.; Kingdom, B.; Sadik, N.; Marques, R. Regulation of Water Supply and Sanitation in Bank Client Countries: A Fresh Look; Water global practice discussion paper; The World Bank: Washington, DC, USA, 2018; Available online: http://documents.worldbank.org/curated/en/252501542747068978/Regulation-ofWater-Supply-and-Sanitation-in-Bank-Client-Countries-A-Fresh-Look (accessed on 11 February 2019).

21. Andres, L.A.; Michael, T.; Camilo, L.C.; Alexander, V.D.; George, J.; Christian, B.-V. Doing More with Less: Smarter Subsidies for Water Supply and Sanitation; World Bank: Washington, DC, USA, 2019.

22. IBNET. The International Benchmarking Network. Available online: https://www.ib-net.org/toolkit/ibnettools/about-benchmarking/ (accessed on 10 February 2019).

23. IBNET Tariffs Dashboard. 2019. Available online: https://tariffs.ib-net.org/ (accessed on 10 February 2019).

24. AquaRating. A Rating System for Water and Sanitation Utilities. Available online: http://www.aquarating.org/ (accessed on 25 February 2019).

25. Inter-American Development Bank. Personal communication, 26 February 2019.

26. International Water Association (IWA). IWA and IDB Launch the Digital Platform 'AquaRating Community of Practice'. 2019. Available online: http://www.iwa-network.org/press/iwa-and-idb-launch-the-aquaratingcommunity-of-practice-that-connects-professionals-around-the-world-to-improve-the-management-ofwater-and-sanitation-services/ (accessed on 25 January 2019).

27. Advani, R. Scaling Up Blended Financing of Water and Sanitation Investments in Kenya; WB Knowledge Note; The World Bank: Washington, DC, USA, 2016; Available online: https://openknowledge.worldbank.org/ bitstream/handle/10986/23996/K8812.pdf?sequence=2\&isAllowed=y (accessed on 15 January 2019).

28. The World Bank. Vietnam Water Sector Reform/Regulation-Review of Urban Water and Wastewater Utility Reform and Regulation; The World Bank: Washington, DC, USA, 2014; Available online: http://documents.worldbank. org/curated/en/886931468125694191/pdf/ACS94240WP0P1496510Box385256B00PUBLIC0.pdf (accessed on 11 February 2019).

29. The World Bank (WB). Facilitated Access to Finance for Domestic Private Water Operators in Cambodia; The World Bank: Washington, DC, USA, 2016; Available online: http://documents.worldbank.org/curated/ en/680211472030707975/pdf/107972-BRI-P159188-BlendedFinanceCasesCambodia-PUBLIC.pdf (accessed on 18 February 2019). 
30. Winpenny, J.; Trémolet, S.; Cardone, R.; Kolker, J.; Kingdom, W.; Mountford, L. Aid Flows to the Water Sector, Overview and Recommendations; The World Bank: Washington, DC, USA, 2016; Available online: http://documents.worldbank.org/curated/en/348721480583568708/Aid-flows-to-the-watersector-overview-and-recommendations (accessed on 29 January 2019).

31. Organisation for Economic Co-operation and Development Project Preparation Committee (OECD). Good Practice in Project Preparation: Public Water Utilities. 2005. Available online: http://www.oecd.org/ env/outreach/34723486.pdf (accessed on 11 February 2019).

32. Soppe, G.; Janson, N.M.; Piantini, S. Water Utility Turnaround Framework: A Guide for Improving Performance; The World Bank: Washington, DC, USA, 2018; Available online: http://documents.worldbank.org/curated/ en/515931542315166330/Water-Utility-Turnaround-Framework-A-Guide-for-Improving-Performance (accessed on 27 January 2019).

33. Global Water Intelligence (GWi). Creating Africa's Most Bankable Water Utility Volume 20. 2019. Available online: https://www.globalwaterintel.com/global-water-intelligence-magazine/ (accessed on 28 February 2019).

34. The World Bank. Uganda-Turnaround of the National Water and Sewerage Corporation. 2003. Available online: https://openknowledge.worldbank.org/handle/10986/9729 (accessed on 27 January 2019).

35. Rossum, S.; Hariram, P. Mobilising infrastructural investments through Water Operators' Partnerships: An example from Mali. Presented at IRC WASH Debate, The Hague, The Netherlands. November 2018. Available online: https://www.slideshare.net/ircuser/mobilizing-infrastructural-investments-through-wateroperators-partnerships-an-example-from-mali (accessed on 11 February 2019).

36. The World Bank. Kenya: Using Private Financing to Improve Water Services; WB Brief; The World Bank: Washington, DC, USA, 2018; Available online: https://www.worldbank.org/en/about/partners/brief/kenyausing-private-financing-to-improve-water-services (accessed on 27 January 2019).

37. International Finance Corporation (IFC) and Water and Sanitation Program (WSP). Public-Private Partnership Stories Benin: Piped Water Supply Systems in Rural and Small Towns. 2015. Available online: https://www.ifc.org/wps/wcm/connect/949fa29d-6e60-4554-8194-a41b3f32b756/PPPStories_ Benin_WSP.pdf?MOD=AJPERES (accessed on 28 January 2019).

38. Lazarte, E.; Senior Water and Sanitation Advisor USAID. Personal communication, 8 February 2019.

39. Marchese, N.; Conference discussion at 2018 Stockholm World Water Week, Stockholm, Sweden.

40. Moise, I.; Barbee, M. Azure: Mobilizing technical services and financial capital to improve water services for small communities in Latin America. Conference presentation; Stockholm, Sweden. 28 August 2018. Available online: https://water.org/globalfinance2018/andhttps:/www.crs.org/media-center/news-release/ crs-and-idbmif-announce-partnership-azure-blended-finance-facility (accessed on 11 February 2019).

41. Water and Sanitation Program (WSP). Lenders' Manual for Commercial Financing of the Water and Sanitation Sector in Kenya; The World Bank: Washington, DC, USA, 2015; Available online: https://www.wsp.org/sites/wsp.org/ files/publications/WSP-Lenders-Toolkit-Commercial-Financing-Water-Sanitation-Kenya.pdf (accessed on 11 February 2019).

42. Ndiso, J.; Malalo, H. Kenya's Parliament Approves Retaining Interest Rate Cap, Against IMF Wishes; Reuters: London, UK, 2018; Available online: https://uk.reuters.com/article/uk-kenya-economy/kenyas-parliamentapproves-retaining-interest-rate-cap-against-imf-wishes-idUKKCN1LF1L4 (accessed on 31 January 2019).

43. Smiet, F. Catalysing WASH: From Possible to profitable; an overview. In Proceedings of the IRC WASH Debate, The Hague, The Netherlands, November 2018; Available online: https://www.slideshare.net/ircuser/ catalyzing-wash-from-possible-to-profitable-an-overview (accessed on 29 January 2019).

44. Steel, W.F.; Darteh, B. Strategies for Household Sanitation: Ghana's Experience with Output-based Aid and Implementation of the Greater Accra Metropolitan Area Sanitation \& Water Project; Consultant report prepared for the Global Partnership for Output-based Aid (GPOBA) and the Ghana Ministry of Sanitation and Water Resources; World Bank: Washington, DC, USA, 2018.

(C) 2019 by the authors. Licensee MDPI, Basel, Switzerland. This article is an open access article distributed under the terms and conditions of the Creative Commons Attribution (CC BY) license (http://creativecommons.org/licenses/by/4.0/). 